\title{
Anticancer effects of fucoxanthin and fucoxanthinol on colorectal cancer cell lines and colorectal cancer tissues
}

\author{
KAZUTO TAKAHASHI ${ }^{1,2}$, MASASHI HOSOKAWA ${ }^{1}$, HIROYUKI KASAJIMA ${ }^{3}$, \\ KAZUTERU HATANAKA ${ }^{3}$, KAZUHIRO KUDO ${ }^{2}$, NORIHIKO SHIMOYAMA ${ }^{2}$ and KAZUO MIYASHITA ${ }^{1}$ \\ ${ }^{1}$ Faculty of Fisheries Sciences, Hokkaido University, Hakodate, Hokkaido 041-8611; \\ Departments of ${ }^{2}$ Clinical Pathology and ${ }^{3}$ Digestive Surgery, \\ Hakodate Municipal Hospital, Hakodate, Hokkaido 041-8680, Japan
}

Received August 18, 2014; Accepted April 29, 2015

DOI: $10.3892 / 01.2015 .3380$

\begin{abstract}
Colorectal cancer is one of the most malignant neoplasms worldwide. Fucoxanthin is a carotenoid present in the chloroplasts of brown seaweeds. In the present study, the anticancer effects of fucoxanthin and its metabolite, fucoxanthinol, on 6 colorectal cancer cell lines and 20 tissue samples from surgically resected clinical colorectal cancer specimens were examined using a collagen-gel droplet embedded culture drug sensitivity test (CD-DST). The in vitro sensitivity to fucoxanthin, fucoxanthinol and the anticancer drugs is expressed as $\mathrm{T} / \mathrm{C}(\%)$, where $\mathrm{T}$ is the absorbance of cells which stained by neutral red treated with carotenoids and $\mathrm{C}$ is the absorbance of non-staining cells. Fucoxanthin and fucoxanthinol decreased the T/C (\%) of Caco-2, WiDr, HCT116, and DLD-1 cell lines at doses of $20 \mu \mathrm{M}$. Fucoxanthinol also decreased the T/C (\%) of SW620 cells, while the T/C (\%) of Colo205 cells was not reduced by treatment with either carotenoid. Specifically, the $\mathrm{T} / \mathrm{C}(\%)$ of Caco-2 and WiDr cells, which were incubated in carotenoid-free medium for 6 days following treatment with $20 \mu \mathrm{M}$ fucoxanthinol for $24 \mathrm{~h}$, was markedly decreased to $1.4 \pm 0.2$ and $12.0 \pm 0.3 \%$, respectively. Furthermore, fucoxanthin and fucoxanthinol decreased the T/C (\%) in colorectal cancer tissue samples. Notably, $20 \mu \mathrm{M}$ fucoxanthinol treatment resulted in a higher proportion of colorectal cancer samples with a T/C $(\%)$ of $<50 \%(13 / 20,65 \%)$ compared with samples treated with $20 \mu \mathrm{M}$ fucoxanthin $(2 / 20,10 \%)$. The median T/C (\%) value of $35.1 \%$ for the 20 cancers specimens treated with $20 \mu \mathrm{M}$ fucoxanthinol was lower than the median $\mathrm{T} / \mathrm{C}(\%)$ values of $86.3 \%$ and $75.8 \%$ for those treated with fluorouracil and paclitaxel, respectively. These results
\end{abstract}

Correspondence to: Mr. Kazuto Takahashi, Faculty of Fisheries Sciences, Hokkaido University, 3-1-1 Minato, Hakodate, Hokkaido 041-8611, Japan

E-mail: k-takahashi@hospital.hakodate.hokkaido.jp

Key words: fucoxanthin, fucoxanthinol, colorectal cancer, anticancer effects suggested that fucoxanthin and fucoxanthinol may be of use as chemotherapeutic agents in colorectal cancer.

\section{Introduction}

Colorectal cancer is one of the most malignant neoplasms worldwide: It was diagnosed as the third most common malignancy in males and as the second most common in females, with $>1.2$ million new cancer cases and 608,700 deaths estimated to have occurred in 2008 (1). Its incidence in developed countries continues to increase, due to westernized eating habits, obesity, smoking, excessive alcohol intake and a lack of exercise, which are all risk factors for the development of colorectal cancer (2). The primary treatments for colorectal cancer are chemotherapy and surgery. Recent advances in systemic chemotherapy have improved outcomes for patients with colorectal cancer (3). However, in order to provide therapeutic benefits for a wider range of patients, the development of a greater number of effective treatment options is necessary.

Fucoxanthin is a marine carotenoid that is present in edible brown seaweeds (4). Previous studies have reported that fucoxanthin exhibits anticancer effects in human neoplastic cell lines, derived from the colorectum, prostate, urinary bladder and liver, and from leukemic cells (5-9). Furthermore, these effects are dependent on its unique molecular structure, which includes an allenic bond and an epoxide. In addition, fucoxanthinol, which is a deacetylated derivative of fucoxanthin, has been reported to induce apoptosis in the Caco-2 human colorectal cancer cell line (10). The anticancer effects of fucoxanthin and fucoxanthinol are hypothesized to be caused by apoptosis induction and cell cycle termination $(5,8,10)$. However, because colorectal cancer evolves through a multistep process, which is characterized by the accumulation of genetic alterations, varying responses to anticancer agents are observed among different colorectal cancer cell lines. Determination of the anticancer activity of these drugs in several cancer cell lines is therefore important in order to clarify potential uses of fucoxanthin and fucoxanthinol as chemotherapeutic agents. Furthermore, investigation of the anticancer effects of fucoxanthin and fucoxanthinol on primary colorectal cancer samples resected from patients is required, in order to examine the sensitivity of human tissue to these drugs, and may advance their use in a clinical setting. 
The present study investigated the anticancer effects of fucoxanthin and fucoxanthinol, using 6 colorectal cancer cell lines and 20 surgically resected colorectal cancer tissue samples. In order to evaluate their anticancer activity, a collagen-gel droplet embedded culture drug sensitivity test (CD-DST) (11-13), which is authorized by the Japanese Public Medical Insurance as an anticancer drug sensitivity test, was employed. This method is suitable for use in various types of fresh cancer specimens and aids in the evaluation of chemosensitivity to drugs.

\section{Materials and methods}

Materials. Fucoxanthin and fucoxanthinol were obtained from WAKO Pure Chemical Co., Ltd. (Osaka, Japan). Fluorouracil and paclitaxel were obtained from Kyowa Hakko Kirin Co., Ltd. (Tokyo, Japan) and Nippon Kayaku Co., Ltd. (Tokyo, Japan), respectively. DF (10) medium (Dulbecco's modified Eagle' medium/F-12; Gibco, Grand Island, NY, USA) was supplemented with $10 \% \mathrm{FBS}, 0.5 \mathrm{mg} / \mathrm{ml}$ piperacillin sodium (Toyama Chemical Co., Ltd., Tokyo, Japan), 0.25 mg/ml kanamycin sulfate (Meiji Seika Pharma Co., Ltd., Tokyo, Japan), $10 \mu \mathrm{g} / \mathrm{ml}$ vancomycin hydrochloride (Kobayashi Kako Co., Ltd., Fukui, Japan) and $1.25 \mu \mathrm{g} / \mathrm{ml}$ amphotericin B (Sumitomo Dainippon Pharma Co., Ltd., Osaka, Japan).

Colorectal cancer cell lines. The DLD-1 (ATCC CCL-221), HCT116 (ATCC CCL-247), SW620 (ATCC CCL-227), Caco-2 (ATCC HTB-37), Colo205 (ATCC CCL-222) and WiDr (ATCC CCL-218) human colorectal cancer cell lines were obtained from the American Type Culture Collection (Manassas, VA, USA).

Clinical colorectal cancers. Surgically resected colorectal cancer specimens were obtained from 20 patients (12 males and 8 females; mean age, 68.5 years; age range, 39-82 years) from 2011 until 2013. Informed consent to measure fucoxanthin and fucoxanthinol sensitivities was obtained from all patients. The present study was approved by the ethics committee at Hakodate Municipal Hospital (Hokkaido, Japan).

$C D$-DST. CD-DST was performed as described previously by Kobayashi et al (11-13). Surgically resected tissue was cut into small pieces and washed several times with saline supplemented with $0.5 \mathrm{mg} / \mathrm{ml}$ piperacillin sodium, $0.25 \mathrm{mg} / \mathrm{ml}$ kanamycin sulfate, $10 \mu \mathrm{g} / \mathrm{ml}$ vancomycin hydrochloride and $1.25 \mu \mathrm{g} / \mathrm{ml}$ amphotericin B. The tissue sections were finely minced using a razor blade and digested in a cell dispersion enzyme solution (EZ; Kurabo, Osaka, Japan) for $2 \mathrm{~h}$ with rotation. The pellet was separated by centrifugation at $250 \mathrm{x} g$ for $3 \mathrm{~min}$. The supernatant was then removed and the pelleted cells were treated with $1 \mathrm{mM}$ EGTA- $0.03 \%$ trypsin for $3 \mathrm{~min}$. DF medium was added by gentle pipetting and resuspended cells were filtered through a $300-\mu \mathrm{m}$ nylon mesh. The collected cells were cultured in PCM-1 medium (Kurabo). Cells were then pre-incubated for $24 \mathrm{~h}$ at $37^{\circ} \mathrm{C}$, and viable cells that adhered to the collagen gel were collected by dissolving the gel using collagenase (C0130; Sigma-Aldrich, St. Louis, MO, USA) in a flask containing collagen gel (CG-flask; Kurabo). Only viable cells were suspended in the reconstructed type I collagen solution (Cellmatrix Type CD; Kurabo) at a final density of $5 \times 10^{4}-2 \times 10^{5}$ cells $/ \mathrm{ml}$. The collagen-suspended cells were dropped onto a 6-well plate, in order to prepare 3 drops of $30 \mu \mathrm{l}$ each and were gelated at $37^{\circ} \mathrm{C}$ in a $5 \% \mathrm{CO}_{2}$ incubator for $1 \mathrm{~h}$. DF medium was overlaid on each well, and the plate was incubated in $5 \% \mathrm{CO}_{2}$ at $37^{\circ} \mathrm{C}$ overnight. Fucoxanthin or fucoxanthinol (3 $\mu \mathrm{l})$ solution dissolved in DMSO was added into the $3 \mathrm{ml}$ of culture medium of each well, and the final concentrations were adjusted to 5,10 or $20 \mu \mathrm{M}$. Plates were maintained at $37^{\circ} \mathrm{C}$ in the $5 \% \mathrm{CO}_{2}$ incubator with $100 \%$ humidity for $24 \mathrm{~h}$. In addition, wells were prepared with fluorouracil or paclitaxel, at a final concentration of $1 \mu \mathrm{g} / \mathrm{ml}$. Following incubation, DF medium containing the carotenoids or the conventional anticancer drugs was removed, and each well was rinsed twice with DF, which did not contain FBS, overlaid with serum-free culture medium PCM-2 (Kurabo), and incubated for 6 days. On the fourth day of incubation, the PCM-2 medium was replaced. At the end of the cultivation, $30 \mu \mathrm{l}$ of Neutral Red (Kurabo) solution was added to each well at a final concentration of $50 \mu \mathrm{g} / \mathrm{ml}$ and viable cells were stained in a $5 \% \mathrm{CO}_{2}$ incubator at $37^{\circ} \mathrm{C}$ for $2 \mathrm{~h}$. After removing PCM-2 medium containing Neutral Red, cells were fixed with $10 \%$ neutral formalin buffer, washed in water, air dried and quantified by image analysis (High-resolution Video Microscope VH-5910, Keyence, Osaka, Japan). The in vitro sensitivity to fucoxanthin, fucoxanthinol and the anticancer drugs is expressed as $\mathrm{T} / \mathrm{C}(\%)$, where $\mathrm{T}$ is the absorbance of cells which stained by neutral red treated with carotenoids and $\mathrm{C}$ is the absorbance of non-staining cells. A T/C (\%) of $\leq 50 \%$ was considered to indicate efficacy of an agent in vitro. In addition, a $\mathrm{T} / \mathrm{C}(\%)$ reduction that was $>2$ standard deviations ( $\mathrm{T} / \mathrm{C}(\%)<80 \%)$ was considered to be significant since the standard deviation of the control group of the clinical colorectal cancers was $100 \% \pm 10 \%$ (data not shown).

\section{Results}

Anticancer effects of fucoxanthin and fucoxanthinol on colorectal cancer cell lines. The sensitivity of colorectal cancer cell lines to fucoxanthin and fucoxanthinol was estimated using CD-DST, which analyzes sensitivity to anticancer drugs and has been clinically applied in individualized chemotherapy (9-11). Treatment with $20 \mu \mathrm{M}$ fucoxanthin decreased the T/C (\%) of Caco-2, WiDr and HCT116 cell lines (Table I). Furthermore, fucoxanthinol decreased the T/C (\%) of SW620 and DLD-1 cells in a similar manner to the three cell lines affected by fucoxanthin, although fucoxanthin did not affect the SW620 or DLD-1 cell lines. In all colorectal cancer cell lines, the $\mathrm{T} / \mathrm{C}(\%)$ of fucoxanthinol-treated cells was lower than that of fucoxanthin-treated cells at a dose of $20 \mu \mathrm{M}$. In particular, the T/C (\%) values of Caco-2 and WiDr cells that were incubated for 6 days following $24 \mathrm{~h}$ treatment with $20 \mu \mathrm{M}$ fucoxanthinol, markedly decreased to $1.4 \pm 0.2 \%$ and $12.0 \pm 0.3 \%$, compared with $73.9 \pm 4.0 \%$ and $65.3 \pm 2.6 \%$, respectively, for the same cell lines treated with fucoxanthin. By contrast, the T/C (\%) of Colo205 cells did not decrease following treatment with either carotenoid. By contrast, the $\mathrm{T} / \mathrm{C}(\%)$ of Colo205 cells did not become less than $80 \%$ following treatment with fucoxanthin or fucoxanthinol. 
Table I. Sensitivity (T/C\%) of colorectal cancer cell lines to various doses of fucoxanthin and fucoxanthinol.

\begin{tabular}{|c|c|c|c|c|c|c|}
\hline \multirow[b]{2}{*}{ Cell line } & \multicolumn{3}{|c|}{ Fucoxanthin } & \multicolumn{3}{|c|}{ Fucoxanthinol } \\
\hline & $5 \mu \mathrm{M}$ & $10 \mu \mathrm{M}$ & $20 \mu \mathrm{M}$ & $5 \mu \mathrm{M}$ & $10 \mu \mathrm{M}$ & $20 \mu \mathrm{M}$ \\
\hline Caco-2 & $91.1 \pm 1.8$ & $96.0 \pm 3.8$ & $73.9 \pm 4.0$ & $79.3 \pm 0.9^{\mathrm{a}}$ & $55.2 \pm 3.0^{\mathrm{a}}$ & $1.4 \pm 0.2^{\mathrm{b}}$ \\
\hline WiDr & $93.7 \pm 2.1$ & $77.4 \pm 1.3$ & $65.3 \pm 2.6$ & $100.0 \pm 4.1$ & $75.6 \pm 0.8$ & $12.0 \pm 0.3^{\mathrm{b}}$ \\
\hline SW620 & $96.0 \pm 2.4$ & $89.3 \pm 2.2$ & $104.4 \pm 1.8$ & $76.9 \pm 0.4^{\mathrm{a}}$ & $73.8 \pm 0.9^{\mathrm{a}}$ & $61.3 \pm 0.9^{b}$ \\
\hline HCT116 & $105.4 \pm 3.6$ & $84.5 \pm 2.1$ & $78.2 \pm 1.0$ & $96.7 \pm 1.2$ & $90.9 \pm 1.5$ & $65.0 \pm 1.3^{\mathrm{b}}$ \\
\hline DLD-1 & $95.8 \pm 2.6$ & $84.0 \pm 0.3$ & $85.8 \pm 0.5$ & $96.5 \pm 2.3$ & $87.9 \pm 2.2$ & $77.6 \pm 1.2^{\mathrm{b}}$ \\
\hline Colo205 & $130.2 \pm 1.6$ & $128.1 \pm 1.4$ & $125.4 \pm 0.2$ & $113.4 \pm 1.9^{b}$ & $134.7 \pm 0.2^{\mathrm{a}}$ & $134.9 \pm 2.4$ \\
\hline
\end{tabular}

Data are presented as the mean \pm standard error. Significant difference between fucoxanthin and fucoxanthinol at same dose (paired t-test, $\left.{ }^{\mathrm{a}} \mathrm{P}<0.05,{ }^{\mathrm{b}} \mathrm{P}<0.01\right)$.

Anticancer effects of fucoxanthin and fucoxanthinol in colorectal cancer specimens. Fucoxanthin and fucoxanthinol exhibited dose-dependent anticancer effects in colorectal cancer specimens (Table II). Fucoxanthinol markedly decreased the T/C (\%) of colorectal cancer tissue samples. The proportion of samples treated with $20 \mu \mathrm{M}$ fucoxanthinol, in which the T/C (\%) values were $<50 \%$, was higher $(13 / 20,65 \%)$ than that in samples treated with fucoxanthin $(2 / 20,10 \%)$. Following treatment with $10 \mu \mathrm{M}$ fucoxanthinol, the $\mathrm{T} / \mathrm{C}(\%)$ values of 5 samples were $<50 \%$, and 3 samples exhibited no change following treatment with fucoxanthin or fucoxanthinol. Further, the median T/C (\%) value of the 20 cancer samples was $79.7 \%$ and $35.1 \%$ at $10 \mu \mathrm{M}$ and $20 \mu \mathrm{M}$ fucoxanthinol, respectively, while the median $\mathrm{T} / \mathrm{C}(\%)$ values for samples treated with $10 \mu \mathrm{M}$ and $20 \mu \mathrm{M}$ fucoxanthin were $94.6 \%$ and $80.6 \%$, respectively.

The conventional anticancer drugs, fluorouracil and paclitaxel, also reduced the T/C (\%) of colorectal cancer samples. Fluorouracil treatment resulted in $\mathrm{T} / \mathrm{C}(\%)$ values of samples from $52.3 \pm 6.8-113.4 \pm 5.5 \%$. A T/C $(\%)$ value $<50 \%$ was not observed in any of the samples treated with $1.0 \mu \mathrm{g} / \mathrm{ml}$ fluorouracil, which is the standard concentration administered to patients with colorectal cancer $(11,12)$. Paclitaxel treatment resulted in T/C (\%) values from $20.1 \pm 1.4-126.6 \pm 5.2 \%$. T/C (\%) values $<50 \%$ were observed in 5 of 19 cases $(26.3 \%)$ treated with $1.0 \mu \mathrm{g} / \mathrm{ml}$ paclitaxel. The median T/C (\%) values of the 20 samples treated with fluorouracil and paclitaxel were 86.3 and $75.8 \%$, respectively, which are approximately the same levels as those of samples treated with $20 \mu \mathrm{M}$ fucoxanthin and $10 \mu \mathrm{M}$ fucoxanthinol. Furthermore, treatment with 10 and $20 \mu \mathrm{M}$ fucoxanthinol reduced the $\mathrm{T} / \mathrm{C}(\%)$ of drug-resistant colorectal cancer samples, including cases 3 and 4 , in which fluorouracil and paclitaxel did not exert anticancer effects. In addition, case 2 had a diagnosis of malignant melanoma, based on the pathological findings from immunohistochemical staining that demonstrated distinct melanin granules. Fucoxanthin and fucoxanthinol also exhibited anticancer effects in the malignant melanoma sample, at doses of 20 and $10 \mu \mathrm{M}$, although fluorouracil and paclitaxel did not. Thus, the anticancer effects of fucoxanthin and fucoxanthinol on colorectal cancer samples differed from those of fluorouracil and paclitaxel.

\section{Discussion}

Fucoxanthin is a carotenoid that is present in the chloroplasts of brown seaweeds. It possesses a unique molecular structure, with an unusual allenic bond and a 5,6-monoepoxide (5). In the gastrointestinal tract of mice, fucoxanthin has been shown to be converted to fucoxanthinol by deacetylation (14). It has been reported that fucoxanthinol and another metabolite of fucoxanthin, amarouciaxanthin A, are accumulated in a number of tissues, such as the liver, adipose tissue and large intestine of mice $(15,16)$. Furthermore, fucoxanthinol has been detected in the serum of human subjects following ingestion of brown seaweed lipids (17).

The present study investigated the anticancer effects of fucoxanthin and fucoxanthinol on 6 colorectal cancer cell lines and in 20 cases of colorectal cancer specimens. The CD-DST used in the current study, employs a collagen gel three-dimensional assay to culture cancer cells, which mimics the environment of the human body. Therefore, the CD-CST is able to provide valuable data, with which to select effective drugs, and has been applied in the assessment of chemotherapy administered in clinical practice.

Fucoxanthin and fucoxanthinol exhibited dose-dependent anticancer effects, as shown by the reduction in T/C (\%) values in colon cancer cell lines and colorectal cancer specimens. Furthermore, fucoxanthinol exhibited a stronger anticancer effect than that of fucoxanthin (Table I and II). The present results support the hypothesis that fucoxanthin is metabolized to the more active fucoxanthinol, which inhibits cancer cell growth. Previously, this group has reported that fucoxanthin and fucoxanthinol induce apoptosis in the colon cancer cell line, Caco-2, through downregulation of BCL-2 $(5,10)$. It has also been reported that fucoxanthin induces cytostasis by terminating the cell cycle in WiDr cells (18). Therefore, apoptosis induction and cytostasis are possible mechanisms underlying the anticancer effects observed in Caco-2 and WiDr cells, in addition to the effects observed in the other colorectal cancer cell lines investigated in the present study, with the exception of Colo205 cells.

Furthermore, fucoxanthin and fucoxanthinol decreased the $\mathrm{T} / \mathrm{C}(\%)$ in colorectal cancer samples. The median T/C (\%) value of the 20 samples treated with $10 \mu \mathrm{M}$ fucoxanthinol 


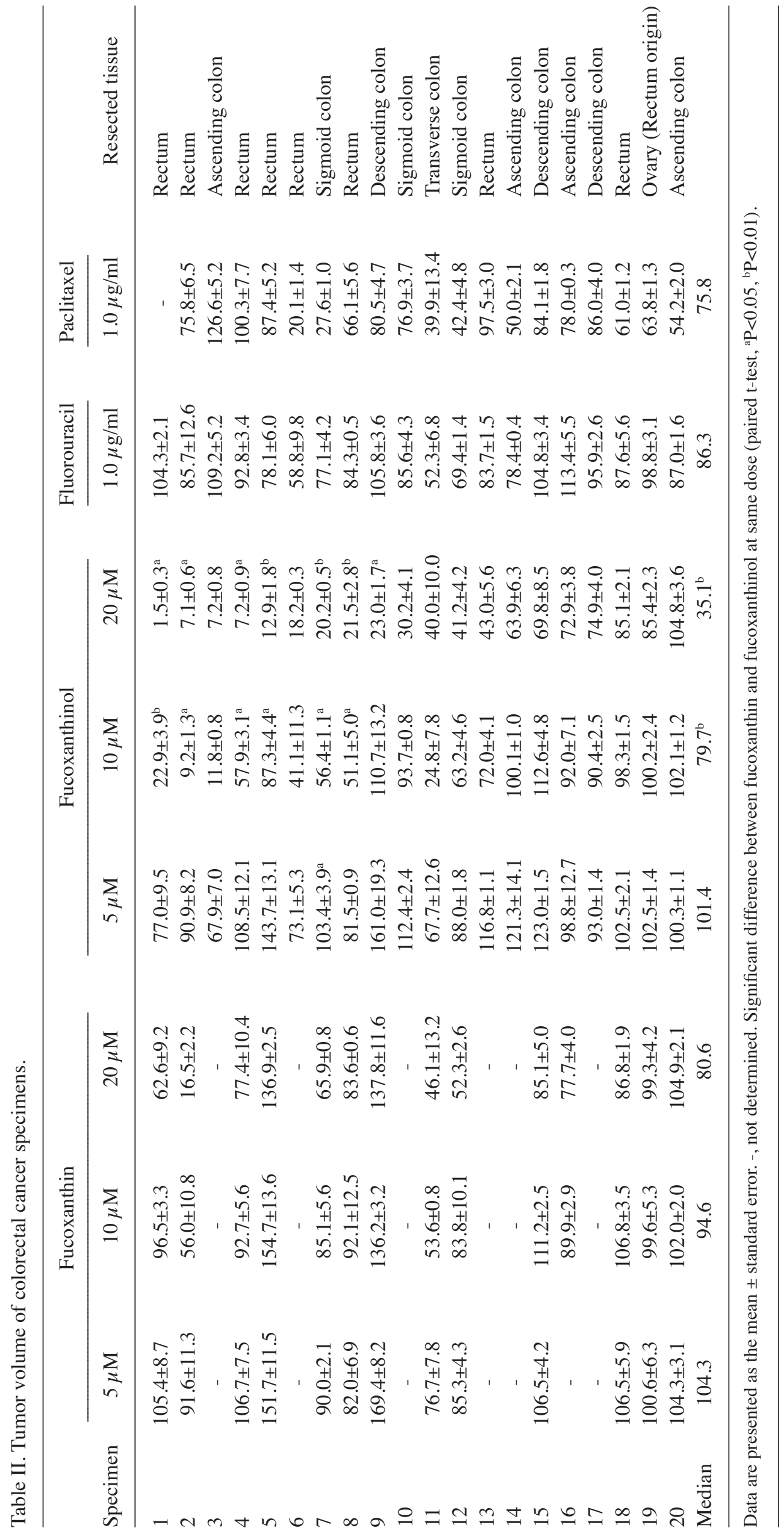


was similar to those of samples treated with fluorouracil and paclitaxel $1 \mu \mathrm{g} / \mathrm{ml}$, which is the standard dose of these drugs in clinical practice $(11,12)$. It is notable that $20 \mu \mathrm{M}$ fucoxanthin and fucoxanthinol treatments markedly decreased the $\mathrm{T} / \mathrm{C}(\%)$ of a specimen (case 2 ) that had been diagnosed as malignant melanoma following histological examination, while fluorouracil and paclitaxel had no effect at $1 \mu \mathrm{g} / \mathrm{ml}$. Fucoxanthin has previously been reported to inhibit the growth of B16F10 melanoma cells in vitro and in vivo (19). An anticancer effect of fucoxanthin in the SK-MEL-28 malignant melanoma cell line, has also been observed (20). Thus, the anticancer effects of fucoxanthin and fucoxanthinol on cancer cells used in the present study differ from those exerted by the anticancer drugs, fluorouracil and paclitaxel. In addition, the carotenoids appeared to exert anticancer effects on types of malignant tumors, other than adenocarcinoma. Furthermore, non-responders, who are insensitive to conventional anticancer drugs, often require individualized chemotherapy to identify effective anticancer drugs. Therefore, a combination of anticancer drugs and fucoxanthinol may improve outcomes in response to chemotherapy in these patients, and facilitate the development of novel treatments for colorectal cancer. Further investigation of the anticancer effects of fucoxanthin and fucoxanthinol is therefore required.

To the best of our knowledge, the present study demonstrated for the first time, the anticancer effects of fucoxanthin and fucoxanthinol in colorectal cancer specimens that had been resected surgically from patients, in addition to colorectal cancer cell lines. Specifically, treatment with fucoxanthinol, which is converted from fucoxanthin in the gastrointestinal tract, resulted in marked reduction of $\mathrm{T} / \mathrm{C}(\%)$ in clinical colorectal cancer specimens. Since fucoxanthin, which is contained in edible brown seaweeds, has been shown to be non-toxic (21), it may be suitable for clinical application in the treatment of colorectal cancer.

\section{Acknowledgements}

The authors would like to thank Mr. Yasutomo Saito, Ms. Manami Yoshida, Ms. Chisato Nakagawa, and Ms. Yuko Maruoka who assisted with the experiments. Thanks are also extended to Dr Hisayuki Kobayashi who provided instruction in cell culture technique.

\section{References}

1. Jemal A, Bray F, Center MM, Ferlay J, Ward E and Forman D: Global cancer statistics. CA Cancer J Clin 61: 69-90, 2011.

2. Wei EK, Giovannucci E, Wu K, Rosner B, Fuchs CS, Willett WC and Colditz GA: Comparison of risk factors for colon and rectal cancer. Int J Cancer 108: 433-442, 2004.

3. Simmonds PC: Palliative chemotherapy for advanced colorectal cancer: Systematic review and meta-analysis. Colorectal Cancer Collaborative Group. BMJ 321: 531-535, 2000.
4. Miyashita K, Nishikawa S, Beppu F, Tsukui T, Abe M and Hosokawa M: The allenic carotenoid fucoxanthin, a novel marine nutraceutical from brown seaweeds. J Sci Food Agric 91: 1166-1174, 2011

5. Hosokawa M, Kudo M, Maeda H, Kohno H, Tanaka T and Miyashita K: Fucoxanthin induces apoptosis and enhances the antiproliferative effect of the PPARgamma ligand, troglitazone, on colon cancer cells. Biochim Biophys Acta 1675: 113-119, 2004.

6. Kotake-Nara E, Asai A and Nagao A: Neoxanthin and fucoxanthin induce apoptosis in PC-3 human prostate cancer cells. Cancer Lett 220: 75-84, 2005.

7. Zhang Z, Zhang P, Hamada M, Takahashi S, Xing G, Liu J and Sugiura N: Potential chemoprevention effect of dietary fucoxanthin on urinary bladder cancer EJ-1 cell line. Oncol Rep 20: 1099-1103, 2008.

8. Das SK, Hashimoto T and Kanazawa K: Growth inhibition of human hepatic carcinoma HepG2 cells by fucoxanthin is associated with down-regulation of cyclin D. Biochim Biophys Acta 1780: 743-749, 2008

9. Hosokawa M, Wanezaki S, Miyauchi K, Kurihara H, Kohno H, Kawabata J, Odashima S and Takahashi K: Apoptosis-inducing effect of fucoxanthin on human leukemia cell line HL-60. Food Sci Technol Res 5: 243-246, 1999.

10. Konishi I, Hosokawa M, Sashima T, Kobayashi H and Miyashita K: Halocynthiaxanthin and fucoxanthinol isolated from Halocynthia roretzi induce apoptosis in human leukemia, breast and colon cancer cells. Comp Biochem Physiol C Toxicol Pharmacol 142: 53-59, 2005.

11. Kobayashi H, Tanisaka K, Kondo N, et al: Development of new in vitro chemosensitivity test using collagen gel droplet embedded culture and its clinical usefulness. Gan To Kagaku Ryoho 22: 1933-1939, 1995 (In Japanese).

12. Kobayashi H: Development of a new in vitro chemosensitivity test using collagen gel droplet embedded culture and image analysis for clinical usefulness. Recent Results Cancer Res 161: 48-61, 2003.

13. Kobayashi H: Collagen gel droplet culture method to examine in vitro chemosensitivity. Methods Mol Med 110: 59-67, 2005.

14. Asai A, Sugawara T, Ono H and Nagao A: Biotransformation of fucoxanthinol into amarouciaxanthin A in mice and HepG2 cells: Formation and cytotoxicity of fucoxanthin metabolites. Drug Metab Dispos 32: 205-211, 2004.

15. Hashimoto T, Ozaki Y, Taminato M, Das SK, Mizuno M, Yoshimura K, Maoka T and Kanazawa K: The distribution and accumulation of fucoxanthin and its metabolites after oral administration in mice. Br J Nutr 102: 242-248, 2009.

16. Airanthi MK, Sasaki N, Iwasaki S, Baba N, Abe M, Hosokawa M and Miyashita K: Effect of brown seaweed lipids on fatty acid composition and lipid hydroperoxide levels of mouse liver. J Agric Food Chem 59: 4156-4163, 2011.

17. Hashimoto T, Ozaki Y, Mizuno M, Yoshida M, Nishitani Y, Azuma T, Komoto A, Maoka T, Tanino Y and Kanazawa K: Pharmacokinetics of fucoxanthinol in human plasma after the oral administration of kombu extract. Br J Nutr 107: 1566-1569, 2012.

18. Das SK, Hashimoto T, Shimizu K, Yoshida T, Sakai T, Sowa Y, Komoto A and Kanazawa K: Fucoxanthin induces cell cycle arrest at G0/G1 phase in human colon carcinoma cells through up-regulation of p21WAF1/Cip1. Biochim Biophys Acta 1726: 328-335, 2005

19. Kim KN, Ahn G, Heo SJ, Kang SM, Kang MC, Yang HM, Kim D, Roh SW, Kim SK, Jeon BT, et al: Inhibition of tumor growth in vitro and in vivo by fucoxanthin against melanoma B16F10 cells. Environ Toxicol Pharmacol 35: 39-46, 2013.

20. Imbs TI, Ermakova SP, Fedoreyev SA, Anastyuk SD and Zvyagintseva TN: Isolation of fucoxanthin and highly unsaturated monogalactosyldiacylglycerol from brown alga Fucus evanescens $\mathrm{c}$ agardh and in vitro investigation of their antitumor activity. Mar Biotechnol (NY) 15: 606-612, 2013.

21. Beppu F, Niwano Y, Tsukui T, Hosokawa M and Miyashita K: Single and repeated oral dose toxicity study of fucoxanthin (FX), a marine carotenoid, in mice. J Toxicol Sci 34: 501-510, 2009. 